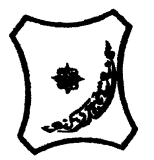

Bayero Journal of Pure and Applied Sciences, 10(2):

$222-225$

Received: June, 2017

Accepted: December, 2017

ISSN $2006-6996$

\title{
VARIATION OF METEOROLOGICAL PARAMETERS AND ITS EFFECT ON REFRACTIVE INDEX OF AIR OVER LAGOS NIGERIA
}

\author{
Bawa, M. ${ }^{1}$,Galadanci G.S.M., ${ }^{2}$ Ayantunji B.G ${ }^{1}$., Mai-Unguwa H. $^{1}$,, Muhammad M.T ${ }^{1}$ and \\ Ibrahim Umar. ${ }^{3}$ \\ ${ }^{1}$ National Space Research and Development Agency, Abuja, Nigeria; ${ }^{2}$ Bayero University, Kano, Nigeria; ${ }^{3}$ Federal \\ Polytechnic, Kaura Namoda, Nigeria \\ *Correspondence author: mbgusau21@gmail.com, Tel: 08037260380, 07038017905
}

\begin{abstract}
Variations of meteorological parameters affect the refractive index in the lower atmosphere. In this study, three years (2011-2013) results of measurements of Atmospheric pressure, Temperature, and Relative humidity from Davis Vantage pro2 automatic weather station installed at the ground surface at Lagos $\left(6^{\circ} 27^{\prime} N, 5^{\circ} 12^{\prime}\right.$ E) Lagos State, were used to examine the effects of meteorological parameters on refractive index using International Telecommunication Union (ITU$R$ ) model. The results show that average hourly variations of refractivity in the dry season is largely as a result of the variations of the wet component (humidity) while the average daily variations of surface radio refractivity in the rainy season is as a result of the variations of the dry (pressure) component of surface radio refractivity. Refractivity reveals seasonal variations with high values in the rainy season and low values in the dry season over the location. The seasonal variation of refractivity of the troposphere is a function of climatic condition while the hourly or diurnal variation of refractivity depends on local meteorology as observed from the results obtained from study location.
\end{abstract}

Keywords: Refractivity, Temperature, Atmospheric pressure, Relative Humidity

\section{INTRODUCTION}

The inhomogeneity of refractive index of air resulted from the variations of meteorological parameters causes adverse effects such as multipath, fading and interference. These effects significantly impair radio communication, aero-space, environmental monitoring, disaster forecasting e.t.c. The effect of meteorological variable of pressure, temperature, and relative humidity on radio wave propagation at UHF and microwaves frequencies are analyzed from the study of radio refractive index derived from these three parameters (Bean and Dutton, 1966). Since these variables vary considerably daily and seasonally especially in the tropics, quantitative knowledge of refractivity variations is required in order to be able to design reliable and efficient radio communication (terrestrial and satellite) system.

Refraction is the deflection or bending of electromagnetic waves when they pass from one kind of transparent medium into another. The index of refraction is the ratio of the speed of electromagnetic energy in vacuum to the speed of electromagnetic energy in the observed medium (Diane, 1998). At standard atmosphere conditions near the Earth's surface, the radio refractive index is equal to approximately 1.0003 . Since the value of refractive index is very close to unity, then the refractive index of air in the troposphere is often measured by a quantity called the radio refractivity $\mathrm{N}$, which is defined as the measure of deviation of refractive index $\mathrm{n}$ of air from unity which is scaled-up in parts per million to obtain more amenable figures. Thus $\mathrm{N}$ is dimensionless quantity defined as measured in $\mathrm{N}$ units (Hughest, 1998).

Refractive index can be measured directly or indirectly. The indirect method of determination of the atmospheric refractive index is based on the measurements of meteorological parameters (pressure, temperature, humidity) with subsequent conversion to the refractive index. However, compared to the direct method (Refractometers method), its implementation is easier and the physical interpretation of the observed changes in the refractive index is immediate. The main drawback is an inherent lack of sensitivity (Ayatunji, 2012).

Relevant literatures carried out in Nigeria are: (Ayatunji, et al. 2011;Okoro and Agbo,2012; Adediji, et al. 2013;Falodun and Ajewale, 2005; Kolawole and Owonubi, 1982;Kaissassou, et al. 2013; Ali, et al. 2011;Adeyemi and Kolawale, 1992; Hughes, 1993; Igwe and Adimula, 2009; Kolawole, 1980; Adediji and Ajewale, 2010).

Experiments to be described in this study utilize an indirect measurement, where the value of refractive index is obtained from the atmospheric pressure, temperature and water vapor pressure of the air using empirical formula provided by International Telecommunication Union.

According to ITU-R (2012), the atmospheric refractive index, $n$, can be computed by using:

$$
N=77.6 \frac{P}{T}+3.73 \times 10^{5} \frac{e}{T^{2}} .
$$

$N=\langle n-1\rangle \times 10^{-6}$,

where, $\mathrm{N}$ is radio refractivity, $\mathrm{P}$ is atmospheric pressure (hpa), e is water vapor pressure (hpa) and $\mathrm{T}$ is absolute temperature $(\mathrm{K})$ 
This expression may be used for all radio frequencies (for frequencies up to $100 \mathrm{GHz}$; the error is less than $0.5 \%$ ) for representative profiles of temperature, pressure and water vapour pressure (Babin et. al. 1997) The water vapor pressure, e, can be calculated from relative humidity as $\boldsymbol{e}=\frac{\boldsymbol{H} e_{s}}{100}$,

where $e_{s}$ is defined as

$\boldsymbol{e}_{s}=\boldsymbol{E} \boldsymbol{F} \cdot \boldsymbol{a} \cdot \exp \left\{\frac{\left\langle b-\frac{t}{d}\right\rangle \cdot \mathrm{t}}{t+c}\right\}$,

and

$$
E F_{\text {water }}=1+10^{-4}\left[7.2 P\left(0.00320+5.9 \cdot 10^{-7} \cdot t^{2}\right)\right] \cdot(5)
$$

Where $e_{s}$ is the water vapour partial pressure, $t$ is temperature in Celsius, $\mathrm{H}$ is the humidity, and constants for water are $a=6.1121, b=18.678, c=257.14$ and $d=234.5$ (ITU-R, 2012).

\section{MATERIAL AND METHODS}

The indirect method of measuring refractivity was employed in this study. Surface values of pressure (hpa), Temperature $\left({ }^{\circ} \mathrm{C}\right)$, and Relative humidity (\%) were extracted from measurements made using Davis Vantage pro2 automatic weather station installed at the ground surface at Lagos $\left(6^{\circ} 27^{\prime} \mathrm{N}, 5^{\circ} 12^{\prime} \mathrm{E}\right)$ Lagos State, a coastal region of Nigeria. The weather stations have five minutes integration time.

Data collected from January 2011 to December 2013 were averaged over each hour to give twenty four data point representing diurnal variations for each day. The hourly data for each day is further averaged to give a data point for the day and average was taken over the month to give a data point for each month which was used to determine the monthly variations for each year. The corresponding months for each year of the three years under study were then averaged to give the average seasonal variations for the period under study. The data were used to compute the surface radio refractivity using equation $2,3,4$ and 5.

\section{RESULTS}
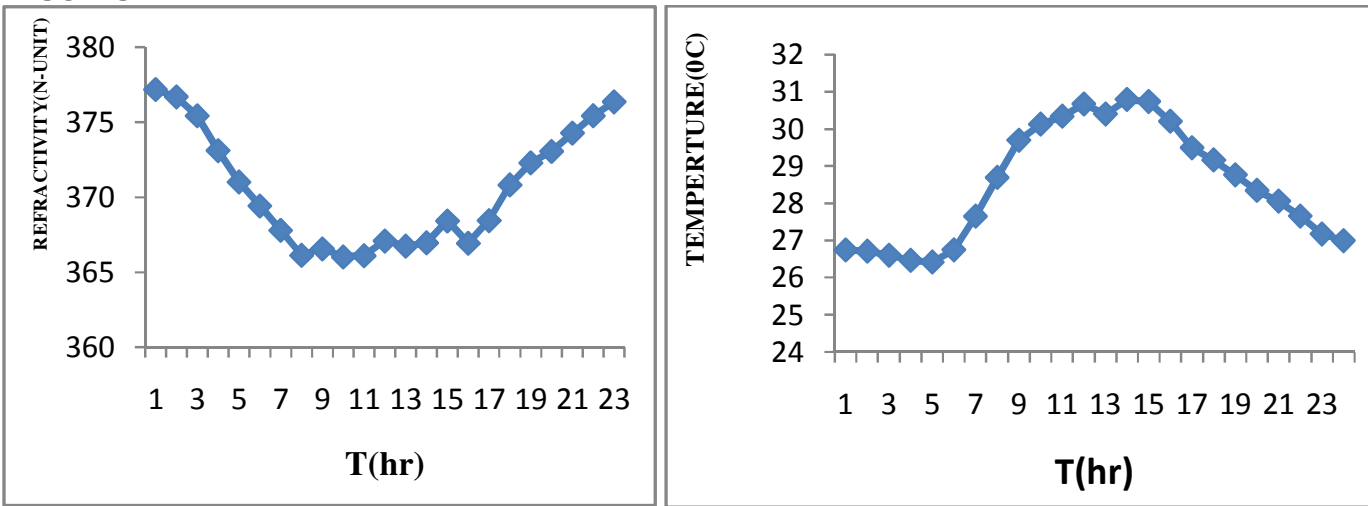

$\begin{array}{llllllllllll}1 & 3 & 5 & 7 & 9 & 11 & 13 & 15 & 17 & 19 & 21 & 23\end{array}$

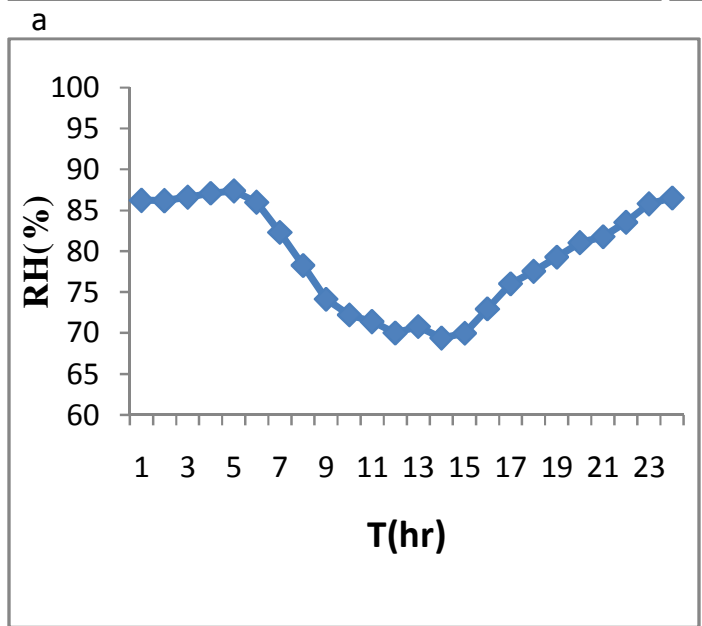

Fig. 1a to 1d. Average Hourly Variations of Surface Radio Refractivity, Temperature, Humidity and Pressure For Dry Season over Lagos from 2011 To 2013 


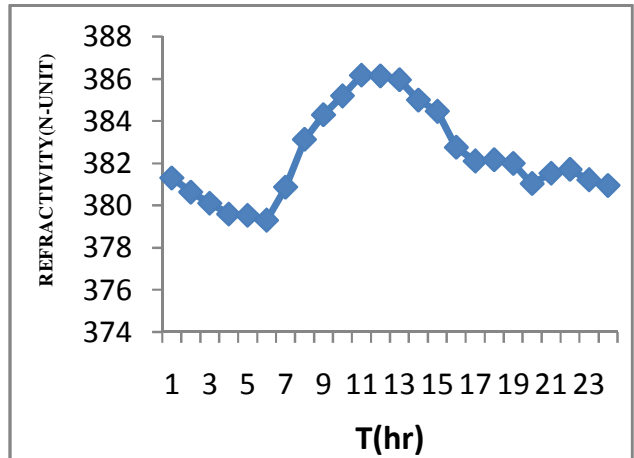

e

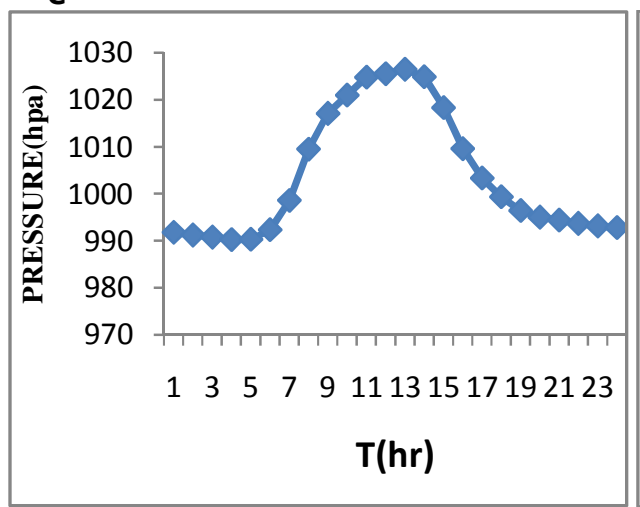

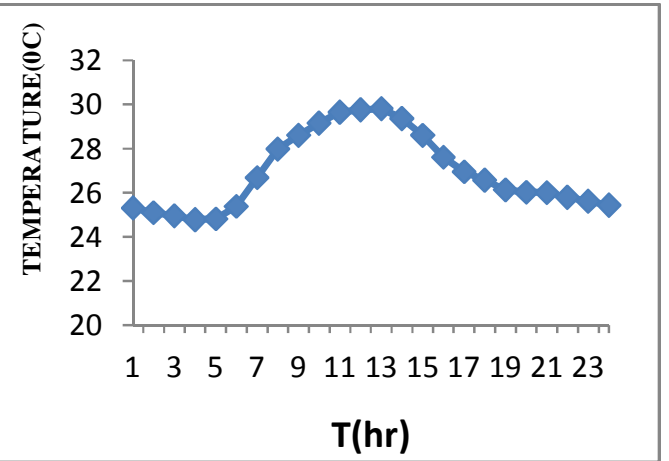

$\mathbf{f}$

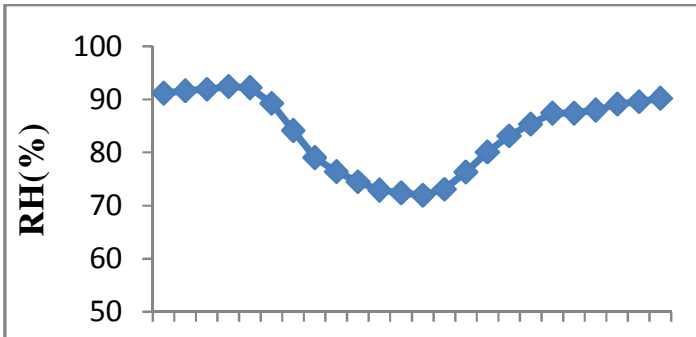

$\begin{array}{lllllllllll}1 & 3 & 5 & 7 & 9 & 11 & 13 & 15 & 17 & 21\end{array}$

$\mathrm{T}(\mathrm{hr})$

$\mathrm{g}$

Fig. 1e to 1h.Average Daily Variations of Surface Radio Refractivity, Temperature, Humidity And Pressure For Rainy Season over Lagos from 2011 To 2013

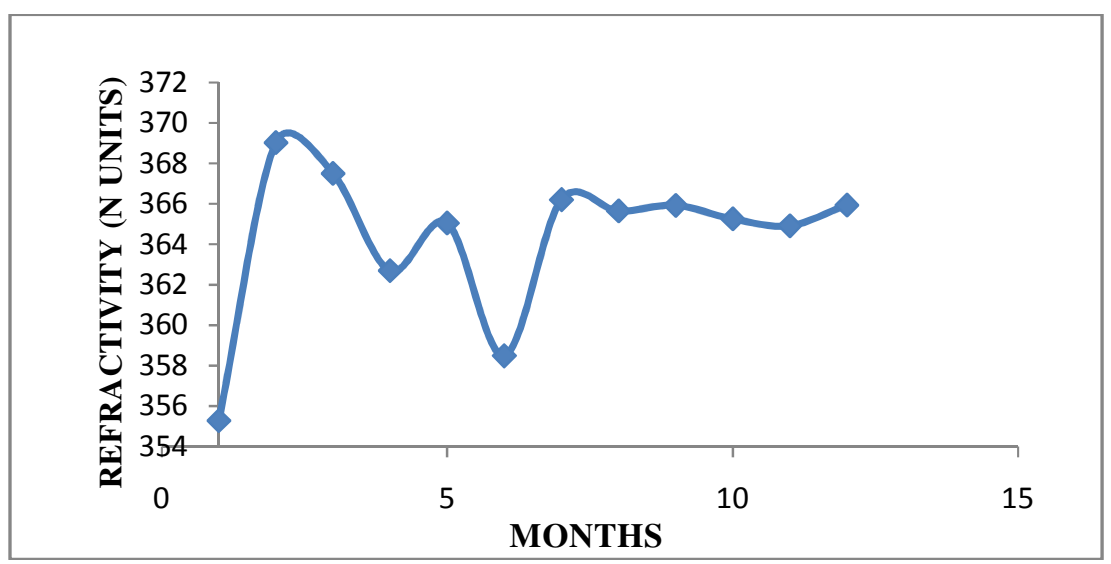

Fig. 2 Average Seasonal Variations of Surface Radio Refractivity over Lagos from 2011 to 2013

\section{DISCUSSION}

The surface radio refractivity in dry season, shows a strong dependence on the wet term (Humidity) of refractivity with high values in the morning and late in the evening and low values in the day time. This is attributed to the response of the earth to solar insolation which is the major force behind the weather condition observed, while the dry component (pressure) is major force driven diurnal variations of refractivity over Lagos during rainy season.

The reduction in precipitation in the months of December to March appears to have no effect on the value of refractivity in these locations. This is because the station is located along the coastal area and the influence of the Atlantic Ocean. A slight drop in the values of refractivity was observed in the months of April and July in this location. The drop in April was attributed to the onset of rainy season while that of July was as a result of slight cessation of rainfall which is usually experienced in August in other locations and is referred as August Break. The minimum value of refractivity was observed in the month of January which coincides with the peak of the harmattan season. The harmattan season is associated with the northeasterly wind which passes over the Sahara desert with its attendance dryness. This result shows that there is no much difference in refractivity value for the dry and rainy season at these 
locations. This observation can be attributed to the presence of the large water body (Atlantic Ocean) at Lagos which makes the relative humidity to be consistently high. This result agrees with work of Ayatunji and Okeke, (2011).

\section{CONCLUSION}

In-situ measurement of temperature, pressure and humidity were carried out at surface of Lagos for a period of three years. The data from these stations were employed to determine the diurnal and seasonal variation of radio refractivity at the station under study using ITU-R Model. The major findings of this study are as follows:

The average hourly variation of refractivity in the dry season is largely as a result of the variations of the wet (Humidity) component of refractivity while the average variations of refractivity in the rainy season is as a result of dry (Pressure) components of refractivity. Hourly or Diurnal variation of refractivity depend on local meteorology as dictated by the topography.

\section{REFERRENCES}

Adediji, A. T. and Ajewole, M. O., (2010). Microwave Anomalous Propagation (AP) Measurement over Akure South-Western Nigeria, Journal of atmospheric and solar-Terrestrial physics, vol. 72, pp 550-555.

Adediji, A. T., Mahamod, I. and Mandeep, J. S., (2013). Variation of radio field strength and radio horizon distance over three stations in Nigeria, Journal of atmospheric and solarTerrestrial physics, vol. 109, pp 1-6

Ali, S., Malik, S. A., Alimgeer, K. S., Khan, K. S. and Ali, R. L., (2011). Statistical estimation of tropospheric radio refractivity derived from 10 years meteorological data, Journal of atmospheric and solar-Terrestrial physics, Vol. 77, pp 196-103

Ayatunji, B. G., (2012). Diurnal and seasonal variation of radio refractivity over Nigeria, PhD thesis, unpublished

Ayatunji, B. G. and Okeke, P. N., (2011). Diurnal and seasonal variation of surface refractivity over Nigeria, Progress in electromagnetic Research B, vol. 30, pp 201-222

Ayatunji, B. G., Okeke, P. N. and Urama, J.O., (2011). Seasonal variation of surface refractivity over Nigeria, Advances in space Research vol. 48, pp 2023-2027

Adeyemi, R. A. and Kolawole, L. B., (1992). Seasonal and Diurnal Variations of Surface Refractivity in Akure, South-Western Nigeria, Unpublished M.Sc Thesis, department of Physics, Federal University of Technology, Akure, Nigeria.

Bean, B. R., Dutton, E. J., (1966). Radio Meteorology, Dover Edition, New York, USA, 120.

Babin, S. M., Young, G. S. and Carton, J. A., (1997). A new model of the oceanic evaporation duct,
- The seasonal variation of refractivity of the troposphere is a function of climatic condition as observed from results obtained from study location.

From the aforementioned findings, the following are some of the applications of this research work.

- $\quad$ The knowledge of meteorological parameters obtained in this study can be useful when planning frequency reuse in the locations.

The surface radio refractivity data obtained in this study will provide radio engineers with adequate information relevant for the design of communication systems in the locations.

\section{- ACKNOWLEDGEMENT}

- $\quad$ The research group acknowledged the effort of the NASRDA, Center for Atmospheric Research under the project, Tropospheric Data Acquisition Network (TRODAN) andCentre for Basic Space Science, University of Nigeria, Nsukka for providing the database for characterization of the troposphere over Nigeria for prediction of impairment for microwave communication.

Journal of Applied Meteorology, Vol. 36, pp 193204.

Diane, F. M., (1998). Basics of Radio Astronomy, California Institute of Technology, Pasadena.

Falodun, S. E. and Ajewole, M.O., (2005). Radio refractive index in the lowest $100 \mathrm{~m}$ layer of the troposphere in Akure, South-western Journal of atmospheric and solar-Terrestrial Physics, Vol. 68 , Pp $236-243$.

Hughes, K. A., (1998). Radio Propagation Data from Tropical Regions: A Brief Review of a seminar on Radio Propagation in Tropical Regions, An unpublished lecture note presented at Centre for Theoretical Physics, Trieste (Italy).

ITU - R., (2012). The refractive index: its formula and refractivity data, Recommendation 203/1, ITU$\mathrm{R}$, Pp 453-9.

Igwe K .C. and Adimula, I. A., (2009). Variation of surface radio refractivity and radio refractive index gradient in sub-sahel, Nigeria journal of space research, vol. 6, pp 135-144.s

Kaissassou, S., Lenouo, A., Tchawoua, C., Lopez, P. and Gaye, A. T., (2014). Climatology of radar anomalous propagation over West Africa, Journal of atmospheric and solar-Terrestrial physics.

Kolawole, L. B., (1980). Climatological Variation of Surface Refractivity in Nigeria, Nigeria Institute of Physics, Vol. 4, Pp 97-117.

Kolawole, L. B., and Owonubi, J. J., (1982). The Surface Radio Refractivity Over Africa, Nigerian Journal of Science, Vol. 16, Nos. 1 \& 2, Pp 441454.

Okoro, O. N. and Agbo, G. A., (2012). The effect of variation of meteorological parameters on tropospheric radio refractivity for minna, Global journals

inc.,

(USA). 